\title{
DO CAMPO PARA O CAMPUS: TRAJETÓRIA DA EDUCAÇÃO DO CAMPO NO BAIXO TOCANTINS
}

\author{
Benedita das Graças Sardinha da SILVA \\ SEMEC/Abaetetuba \\ sardinhadousj@yahoo.com.br \\ Marcos Marques FORMIGOSA \\ SEMEC/Abaetetuba \\ marcosformigosa@gmail.com
}

Resumo: O presente artigo tem como objeto de estudo as políticas públicas para a educação do campo executadas na Universidade Federal do Pará/Campus Universitário de Abaetetuba, com o objetivo de discutir como tais políticas públicas foram implementadas e qual o reflexo dessas no interior da instituição. No processo de pesquisa, escolheu uma abordagem qualitativa, utilizando como metodologia a pesquisa bibliográfica, tendo como fonte de coleta de dados documentos oficiais que dispõem sobre as políticas públicas para a educação do campo no Brasil. Constatou-se, a partir da pesquisa, que essas iniciativas contribuíram para o fortalecimento dos grupos de pesquisa no campus; estreitou as relações entre a instituição e os movimentos sociais, bem como suscitou a preocupação da universidade na formação de professores para atuarem em escolas do campo.

Palavras-chave: Educação do campo. Políticas públicas. Pronera. Procampo.

Abstract: This article is about the study of public policy for rural education implemented at the Federal University of Pará/University Campus Abaetetuba, aiming to discuss how such policies were implemented and what the impact of these within the institution. In the research process, chose a qualitative approach, using as a methodology the literature, and as a source of data collection official documents that have public policy for rural education in Brazil. It was found from the study that these initiatives have contributed to the strengthening of research groups on campus; narrowed relations between the institution and the social movements, and raised the concern of university teacher training to work in schools field.

Keywords: Education field. Public policies. Pronera. Procampo. 


\section{Introdução}

O contexto educacional do Pará apresenta uma realidade complexa, derivada de múltiplos elementos, entre os quais a sociobiodiversidade característica da região amazônica; a extensão territorial do estado; a histórica desigualdade regional, que têm imperado no Brasil e que têm levado esse estado a apresentar baixos resultados em indicadores no Norte do país, com destaque aos indicadores educacionais.

Apesar da expansão do ensino em todos os níveis no país, ainda se observa uma desigualdade educacional histórica entre as regiões e segmentos populacionais, urbanos e rurais, de gênero e étnicos. A precarização do ensino - distorção série-idade, condições físicas e materiais, falta de políticas que garantam a permanência dos alunos com sucesso nos espaços educacionais - é elemento presente na realidade, particularmente no meio rural, que evidencia essa situação.

O que se observa é um modelo educacional precário, marcado, geralmente, por uma escola multisseriada, sem espaços adequados, com baixa ou nenhuma infraestrutura, além de um currículo deslocado do contexto sociocultural dos alunos, conforme Barros $(2006,2007)$ apresenta.

Assim, não proporciona uma educação contextualizada, que possibilite uma formação adequada ao modo de viver, pensar e produzir dos sujeitos do campo. Essas questões são norteadoras para observar o desrespeito às particularidades, à cultura, aos costumes e à diversidade desses sujeitos (BRASIL, 2010).

Essas questões têm motivado o movimento social organizado, intelectuais, instituições de ensino, a somar forças na busca da universalização da educação para os sujeitos do campo, em contraposição às políticas compensatórias do meio rural impostas, conforme Molina e Freitas (2011, p. 22) salientam: “[...] os movimentos sociais do campo, ao fazerem-se porta-vozes dessas reivindicações, sublinham exatamente essa diferença que marca o modo como se elaboram as respostas necessárias à garantia dos direitos historicamente negados".

É necessário construir um desenvolvimento a partir da perspectiva de que campo e cidade são espaços complementares e não espaços isolados, independentes um do outro. O campo é espaço social com vida, 
identidade cultural própria e práticas compartilhadas, socializadas por aqueles que ali vivem (BRASIL, 2007).

Foram essas questões pertinentes que nos levaram a estudar os problemas relacionados sobre a formação dos professores, no âmbito da UFPA, especificamente no Campus Universitário de Abaetetuba. Assim, por meio do Grupo de Estudos e Pesquisa Memória, formação docente e tecnologia (GEPEM), credenciado junto ao CNPq, buscouse elencar as questões formativas presentes dentro do Campus, e, dentre essas questões, destaca-se a formação de professores para a atuação nas escolas do campo.

Assim, por meio de diversos estudos no interior do GEPEM, percebemos a necessidade de se discutir e entender a formação do professor e como essa formação está sendo pautada na agenda das políticas públicas governamentais. Pois é importante que se busquem políticas que proporcione uma formação adequada ao professor, " [...] que contemple a construção de uma sociedade democrática, promotora de uma educação cidadã" (TAVARES, 2004, p. 287). Afinal, segundo essa mesma autora:

[...] O educador não é apenas um distribuidor de conhecimentos socialmente produzidos; há nas especificidades de sua função uma forte exigência de produção da ciência pedagógica, cujo objeto são as concepções e as práticas pedagógicas escolares e não-escolares, construídas com base nas relações sociais e produtivas e seus respectivos fundamentos [...] possibilitando não somente a análise dos conteúdos transmitidos, mas principalmente a utilização de formas metodológicas que permitam a utilização do saber científico, historicamente construído, na compreensão das relações sociais, buscando com esse embasamento intervir na realidade, obtendo, em conseqüência, a produção de novos conhecimentos" (TAVARES, 2004, p. 291-292).

Assim, após um conjunto de reflexão envolvendo as entidades do movimento social e as instâncias do Estado, tem-se buscado "caminhos alternativos" de políticas públicas que sejam capazes de responder aos desafios colocados para as populações que resistem e sobrevivem no campo. Dessa forma, faz-se necessário desenvolver pesquisas em uma 
região que busca a manutenção de atividades econômicas marcadamente desenvolvidas pelo extrativismo, pelo artesanato, pela agricultura familiar, e pela pesca, apesar da forte influência dos grandes projetos implementados na região.

\section{Políticas públicas para o campo: a educação em questão}

A educação do campo conta com respaldo legal para exigir um tratamento diferenciado e específico. A Lei de Diretrizes e Bases da Educação (Lei no 9394/96) estabelece o direito aos povos do campo a um sistema de ensino que "respeite a diversidade do campo em todos seus aspectos sociais, culturais, ambientais, políticos, econômicos, de gênero, geracional e de raça e etnia" (BRASIL, 2010) garantindo, com isso, uma educação emancipatória, "para o desenvolvimento social, economicamente justo e ambientalmente sustentável, em articulação com o mundo do trabalho" (BRASIL, 2010).

Implementar políticas públicas "[...] trata-se de contemplar as especificidades sócio-históricas que foram impressas nas trajetórias pessoais e coletivas de exploração e opressão vividas pelos sujeitos que demandam esses direitos" (MOLINA; FREITAS, 2011, p. 22).

A educação do campo, há tempos, sempre ficou à margem das políticas públicas. E quando inserida nas pautas, geralmente é pensada de forma generalizada, sendo oferecida sem condições de oportunizar os saberes necessários para uma formação cidadã, que atendesse às "singularidades e particularidades nas quais esta se materializa" (MOLINA; FREITAS, 2011, p. 22). O que se observa é que "[...] na maioria das vezes os programas e projetos são pensados por uma "elite culta em gabinetes", sem conhecimento das realidades locais imediatas ou regionais [...] não condizente com as reais condições sociais e políticas dos trabalhadores" (BRANDÃO, 2006, p. 41).

Pelo exposto, é necessário considerar a relevância da educação do campo para o desenvolvimento rural. E o Estado precisa buscar meios para suprir essa dívida histórica com essas populações. $\mathrm{O}$ acesso à educação superior, com prioridade para a formação de professores do campo, para o atendimento da especificidade dessas localidades é uma das políticas públicas que precisa está em pauta. E isso é apresentado por 
Brasil (2010) como um dos princípios dessa modalidade de educação: o "desenvolvimento de políticas de formação de profissionais da educação para o atendimento da especificidade das escolas do campo, considerandose as condições concretas da produção e reprodução social da vida no campo".

A universidade, como "lócus privilegiado para a formação do educador [...], precisa repensar seriamente a questão de sua função social na tensão resultante das mudanças na cultura [...]" (TAVARES, 2004, p. 293-294) e participar ativamente dos "caminhos alternativos", buscando sanar os anseios da população do campo, com a perspectiva de formar professores, segundo Tavares (2004, p. 294), “[...] mais aptos a ensinar além de uma disciplina, a ensinar a aprender, saber avaliar quais as informações relevantes no mundo atual, como e onde recolhê-las e combiná-las para resolver problemas $[\ldots]$ ", na perspectiva de se ofertar uma educação que "[...] deve ser complementada pela intencionalidade de responder às particularidades resultantes do processo histórico que excluiu do acesso à educação a classe trabalhadora do campo" (MOLINA; FREITAS, 2011, p. 22).

Dentre esses "caminhos alternativos", destacam-se o Programa Nacional de Educação na Reforma Agrária (Pronera) e o Programa de Apoio à Formação Superior em Licenciatura em Educação do Campo (Procampo $)^{1}$, desenvolvidos na Universidade Federal do Pará - Campus Universitário de Abaetetuba, como principais políticas públicas para o campo, frutos do protagonismo dos movimentos sociais e sindicais do campo e outras entidades da sociedade civil, inclusive as IES (MOLINA e FREITAS, 2011; FREITAS, 2011).

O movimento social organizado e algumas Instituições Públicas de Ensino Superior (UPES), que congregam o Fórum Regional de

\footnotetext{
${ }^{1}$ Em 2007, foram criadas quatro experiências piloto na Universidade de Brasília (UnB), Universidade Federal de Minas Gerais (UFMG), Universidade Federal da Bahia (UFBA) e Universidade Federal de Sergipe (UFS), com uma média de 50 alunos. A partir dessas experiências, outras universidades vêm criando a Licenciatura em Educação do Campo, num total de 27 (Freitas, 2011), dentre elas a UFPA. Esse Programa está vinculado à Secretaria de Educação Continuada, Alfabetização, Diversidade e Inclusão (SECADI), do Ministério da Educação (MEC).
} 
Educação do Campo da Região Tocantina (FORECAT) ${ }^{2}$, tiveram papel fundamental nessas conquistas.

\section{Pronera: caminhando pelas águas do rio Tocantins}

O Pronera, em âmbito nacional, foi criado por meio da Portaria $\mathrm{n}^{\circ}$. 10 de 16/04/1998, como fruto de um "[...] projeto educacional das IES para os assentamentos [...] na perspectiva de combater os elevados índices de analfabetismo e os baixos níveis de escolarização dos assentamentos" (INCRA, 2004, p. 13).

Atualmente, o Pronera está instituído pelo Decreto Federal $n^{\circ}$ 7.352, que "Dispõe sobre a política de Educação do Campo e o Programa Nacional de Educação na Reforma Agrária - PRONERA". A implantação desse Programa "[...] objetiva a ampliação e a contextualização dos serviços de educação para o meio rural”, (BONNAL; KATO, 2011, p. 78), além "[...] do acesso à educação como um direito" (Idem).

O Pronera tem contribuído significativamente para o contexto atual da educação do campo. Segundo Souza (2011, p. 147 Apud Molina 2008, p. 19-20),

[...] Parte significativa da luta dos sujeitos organizados do meio rural para a construção da Educaşão do Campo tem se dado por meio do Pronera. Os 10 anos de práticas concretas de escolarização dos assentados a completarem-se em 2008, que garantiram a materialidade do Programa, foram fundamentais para a construção da bandeira da Educação do Campo [...].

Conforme Art. 12, do referido decreto, o Pronera tem por objetivos:

${ }^{2}$ O FORECAT é um espaço que se constitui numa articulação de Instituições de Ensino, Pesquisa, Órgãos Governamentais de fomentos ao desenvolvimento e da área Educacional, Entidades da Sociedade Civil e Movimentos Sociais que compartilham princípios, valores e concepções políticas da região, particularmente para os municípios de Abaetetuba, Acará, Barcarena, Igarapé-Miri e Moju, com o objetivo principal de pensar, discutir e construir políticas públicas de educação e de formação permanente do homem do campo, estruturadas a partir da dinâmica da Agricultura Familiar na perspectiva do desenvolvimento socioeconômico inclusivo e sustentável (CORDEIRO, 2010). 
I - oferecer educação formal aos jovens e adultos beneficiários do Plano Nacional de Reforma Agrária - PNRA, em todos os níveis de ensino;

II - melhorar as condições do acesso à educação do público do PNRA; e

III - proporcionar melhorias no desenvolvimento dos assentamentos rurais por meio da qualificação do público do PNRA e dos profissionais que desenvolvem atividades educacionais e técnicas nos assentamentos.

A primeira experiência com Educação do Campo na UFPA/Campus Universitário de Abaetetuba se deu por meio do Pronera, como forma de atender a uma grande demanda, que existe na região, de professores que possua formação adequada para atuarem nas escolas do campo:

\begin{abstract}
Neste contexto o Campus Universitário de Abaetetuba tem desenvolvido uma série de atividades que vem [ao encontro das] demandas propostas pelo movimento social $e$ as necessidades de formação apresentadas pelos órgãos públicos, principalmente àquelas apresentadas pelas secretarias municipais de educação. Entre essas atividades destacamos a Licenciatura Plena em Pedagogia - PEDAGOGIA DAS ÁGUAS [...] através do Programa Nacional de Reforma Agrária (PRONERA). (UFPA, 2009, p. 10).
\end{abstract}

Segundo Souza (2011, p. 29) “[...], o diferencial em relação ao curso regular da Licenciatura em Pedagogia é a oferta voltada, especificamente, para ribeirinhos assentados da reforma agrária das ilhas de Abaetetuba", com um currículo dividido em três núcleos: "[...]: um núcleo de conteúdos básicos, um núcleo de conteúdos específicos e um núcleo eletivo. Portanto, os núcleos serão os elementos lógicos norteadores da formação que se pretende". (UFPA, p. 8). Com isso, conforme UFPA (2005, p. 8), o curso de Pedagogia das Águas busca:

[...] consolidar uma nova identidade profissional do pedagogo, a partir de uma base de formação que contemple um conjunto articulado de conhecimentos mínimos necessários, que o qualifique para atuar nos espaços educativos formais e não-formais numa perspectiva de totalidade. 
Dessa forma, buscou-se, por meio do curso de graduação em Pedagogia das Águas,

I - Elevar a escolaridade de professores(as) de $1^{a}$ a $4^{a}$ série do Ensino Fundamental e do Ensino Médio que atuam nas escolas dos assentamentos da Região das Ilhas de Abaetetuba [...]; e

II - Formar professores(as) para o exercício da docência e das diferentes dimensões do trabalho pedagógico em âmbito formal e não formal, realizado em instituições escolares, movimentos sociais e organizações não-governamentais, além de outros espaços institucionais e não institucionais, e/ou através de ações comunitárias e empresariais (UFPA, 2005, p. 08).

Ao todo, foram ofertadas 50 vagas, no ano de 2006, por meio de processo seletivo especial. Todas as vagas foram preenchidas, e no dia 14 de abril de 2011, a UFPA fez a cerimônia de colação de grau da turma denominada Domingos Trindade Ferreira Pereira (Assopra) $)^{3}$, e outorgou o grau de Licenciados Plenos em Pedagogia a 46 ribeirinhos das ilhas do município de Abaetetuba.

Segundo Souza (2011, p. 05), a proposta inicial do curso de Pedagogia das Águas foi alcançada, pois "[...] os saberes culturais ribeirinhos se fizeram presentes no currículo, de forma efetiva no núcleo eletivo do curso" que possibilitou a "[...] aproximação/afinação, reconhecimento e/ ou sensibilidade para com a vida dos povos ribeirinhos" (SOUZA, 2011, p. 05).

\section{Procampo: para além das águas do Tocantins}

Como descrito anteriormente, foi possível perceber que a evasão no curso de Pedagogia das Águas foi mínima - apenas quatro discentes não concluíram o curso. Além disso, as discussões acerca da importância da formação e da qualificação dos professores que atuam no campo, bem

\footnotetext{
${ }^{3}$ Um dos líderes do movimento social organizado que muito contribuiu para a realização desse projeto, desde sua elaboração, com sua sabedoria ribeirinha, e em muito tem contribuído para a educação do campo, na região do Baixo Tocantins, e que à época coordenava o Movimento dos Ribeirinhos e Ribeirinhas das Ilhas e Várzeas de Abaetetuba (MORIVA).
} 
como da necessidade de formação em nível superior para a juventude do campo estavam bastante amadurecidas no interior do Campus e amplamente apresentada como demanda do movimento social, por meio do FORECAT.

Com isso, a instituição buscou meio que pudesse atender a uma demanda, não apenas da região das ilhas de Abaetetuba, mas também de outros municípios que se congregam ao território do Baixo Tocantins. Assim, um dos "caminhos" encontrados foi o Procampo, que segundo Brasil (2009), tem por objetivo:

A implementação de cursos regulares de Licenciatura em Educação do Campo nas Instituições Públicas de Ensino Superior de todo o país, voltados especificamente para a formação de educadores para a docência nos anos finais do ensino fundamental e ensino médio nas escolas rurais.

A instituição pretende, ainda, enriquecer o debate na formação dos professores das escolas do campo, associando sua formação, por meio de processos educativos contextualizados e sintonizados socioculturalmente com a realidade local e com a diversidade da região (BRASIL, 2009), tendo "como fundamento as especificidades do perfil de educador que se intenciona formar" (MOLINA; FREITAS, 2011).

Além disso, surge como estratégia para a qualificação de profissionais que detenham um perfil voltado para as questões intrínsecas ao campo na Amazônia. Profissionais que sejam capazes de multiplicar conhecimentos e ações no processo de valorização da identidade cultural do homem do campo.

No Campus Universitário de Abaetetuba, o projeto aprovado junto ao MEC contempla as áreas de Ciências Naturais, Linguagem e Matemática e é destinado à formação inicial de $60^{4}$ professores que já atuam em escolas do campo ${ }^{5}$. Segundo Freitas (2011, p. 46), "A formação

\footnotetext{
${ }^{4}$ As 60 (sessenta) vagas ofertadas no Processo Seletivo Especial (PSE) foram dividas em igualdade entre as habilitações e, o candidato deveria optar pela mesma no ato da inscrição do PSE.

${ }^{5}$ Os professores possuem vínculo com os governos municipais e estaduais, movimentos sociais do campo, Casas Familiares Rurais, Escolas Famílias Agrícolas, Escolas de Unidades de Conservação, Áreas Quilombolas e outros da área rural, situadas em contextos sociocultural diversificado da região do Baixo Tocantins, especificamente dos municípios de Abaetetuba, Acará, Barcarena, Igarapé Miri e Moju.
}

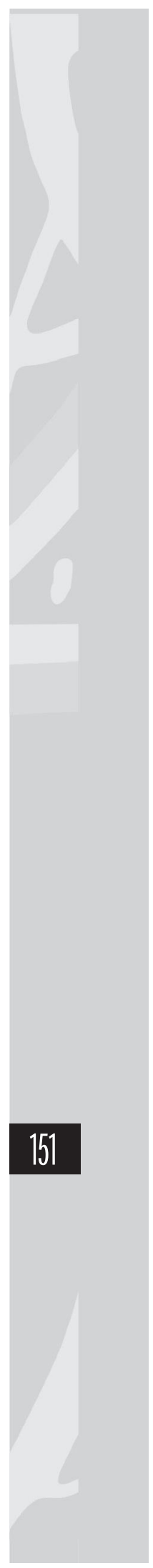


é por área de conhecimento, prevendo a docência multidisciplinar. A matriz curricular desenvolve uma estratégia multidisciplinar de trabalho docente, organizando os componentes curriculares".

Além disso, segundo essa mesma autora:

O curso tem ainda a intenção de preparar educadores para uma atuação profissional que vai além da docência, considerando a gestão dos processos educativos que acontecem na escola e no seu entorno. Todos os aspectos referentes aos projetos de vida desses sujeitos no contexto do desenvolvimento rural local e regional devem ser considerados na formação desses educadores, para que desenvolvam uma visão clara e objetiva de suas potencialidades e possibilidades como sujeitos individuais e coletivos (FREITAS, 2011, p. 46).

Sá (2011, p. 82) também ressalta o perfil do egresso do Curso de Educação do Campo:

[...] o perfil do egresso é o de um educador cuja prática pedagógica esteja baseada numa visão de totalidade da realidade em que ele se insere e numa metodologia de produção de conhecimento que seja pertinente à transformação dessa realidade. Trata-se de uma experiência em construção em que a práxis pedagógica busca constituir o conhecimento científico a partir da complexa trama entre o particular e o universal, o subjetivo e a objetividade, na imbricação com os saberes e experiências das histórias vividas por esses sujeitos.

Para a construção desse perfil, o Projeto Pedagógico do Curso (PPC) propõe que as atividades curriculares sejam desenvolvidas em regime de alternância entre Tempo-Universidade e Tempo-Comunidade, que segundo UFPA (2009, p. 25), é um regime:

Obrigatório, desenvolvido numa abordagem teórico-prática, tornando o fazer pedagógico mais qualitativo, dinâmico e transformador, se constitui uma das condições para a obtenção da licença para o exercício profissional na medida em que é considerado o momento de efetivar, [...] um processo de ensino, aprendizagem em que se tornará concreto, quando da profissionalização deste estagiário. 
Esse regime tem por objetivo "[...] garantir o vínculo dos estudantes com suas comunidades de origem” (FREITAS, 2011, p. 45), ou seja, garantir que eles continuem a viver no campo mesmo depois da conclusão do curso (2011, p. 28), e ainda ressalta a importância dessa organização curricular:

Ao organizar metodologicamente o currículo por alternância entre tempo-escola e tempo-comunidade, a proposta curricular da licenciatura objetiva integrar a atuação dos sujeitos educandos na construção do conhecimento necessário à sua formação de educadores, não apenas nos espaços formativos escolares, como também nos tempos de produção da vida nas comunidades onde se encontram as escolas do campo.

Para implementação do regime de alternância, são realizadas oficinas pedagógicas, elaboradas, inicialmente, nas disciplinas Práticas Pedagógicas I, II, III, IV, V, VI, VII e VIII e são acompanhadas por membros do FORECAT e pela Coordenação Pedagógica do Curso. Nessas disciplinas os alunos são levados a desenvolverem a "capacidade de compreender o processo educativo como espaço interdisciplinar, com vistas à articulação entre a realidade vivenciada pelo aluno e a prática pedagógica das escolas, buscando uma análise global e crítica da realidade educacional” (UFPA, 2009, p. 72).

Após a execução das oficinas, os alunos-cursistas socializam o resultado do trabalho para a comunidade acadêmica por meio de Seminários Integradores, "dentro de uma perspectiva colaborativa de problematização-reflexão e intervenção” (UFPA, 2009, p. 26), reafirmada pela proposta do Núcleo Formador contida no PPC, que segundo UFPA (2009, p. 24), tem por objetivo:

[...] proporcionar ao graduando subsídios para a construção da formação intelectual, visando [à] reafirmaşão da identidade cultural articulando aspectos da docência, memória e práticas educativas na educação do Campo como principais elementos da formação do educador/licenciado (Grifos dos autores). 
Esses núcleos formadores em muito podem contribuir para a reflexão sobre as práticas docentes e os valores sociais que estes têm no contexto educacional, social, político e econômico. Além disso, remetenos à discussão sobre quais "saberes" são necessários aprender para que consigam estabelecer relações do contexto com o mundo.

Todavia, muitas dificuldades vêm sendo encontradas para execução desse programa dentro da UFPA. Por ser um programa do governo federal, o Procampo recebe recursos próprios ${ }^{6}$ para o desenvolvimento de suas atividades. Recursos esses que são repassados para a instituição. Mas, atualmente, segundo a coordenação do Programa no Campus, o governo federal não tem feito o repasse desses recursos para a UFPA. Uma vez que todos os alunos são da zona rural de seus respectivos municípios, eles precisam de espaço para alojamento, bem como para o seu deslocamento. As aulas (conhecido como Tempo Universidade) acontecem em período de férias escolares (janeiro/fevereiro e julho/agosto) e os alunos se deslocam nesses períodos para Abaetetuba.

Isso tem ocasionado uma série de dificuldades para o Campus, que possui um orçamento limitado e ainda atende outras demandas da Unidade. A turma "beneficiada" pelo Procampo já concluiu a $3^{\text {a Etapa }}$ (de um total de 8) do Tempo-Universidade, e, durante a construção desse trabalho, algumas disciplinas a serem ofertadas em janeiro/fevereiro não possuíam professores lotados, pois o curso de Educação do Campo não possui quadro próprio de docentes para ministrarem disciplinas.

Geralmente os docentes são lotados em suas Faculdades, e quando necessitam cobrir seus planos individuais de trabalho (PIT) recorrem ao curso de Educação do Campo para tal. Mas, vale ressaltar que muitos docentes ministram disciplinas com seus PIT já preenchidos, por acreditarem na proposta do trabalho e por não deixarem que este deixe de acontecer. Ou até mesmo professores de outros campi se deslocam para Abaetetuba para contribuírem no processo de formação desses sujeitos

Outra questão que merece destaque é o papel que as entidades que compõem o FORECAT têm desempenhado, oferecendo um grande

\footnotetext{
${ }^{6}$ Esses recursos são destinados exclusivamente para material de consumo, hospedagem e transporte dos alunos, além de pagamento de diárias para acompanhar as oficinas pedagógicas nas comunidades
} 
suporte para o desenvolvimento dessas atividades, seja com recursos financeiros, seja com recursos humanos, em que os próprios participantes do Fórum desenvolvem atividades que vão desde a busca de recursos para o desenvolvimento das atividades até os serviços de limpeza, manutenção, transporte e outros, tudo isso para evitar que o aluno deixe de está em sala de aula para desenvolver tais atividades.

Dessa forma, o governo não garante o andamento tranquilo do programa, retardando ainda mais a qualificação desses sujeitos do campo. Mas, o movimento social, a universidade e os próprios alunos acreditam na melhoria da qualidade da Educação do Campo, na região do Baixo Tocantins.

\section{Algumas Considerações}

É notório que as políticas públicas para os sujeitos do campo vêm sendo ampliadas nos últimos anos. Políticas essas que vão desde a Creche até a Educação Superior. Todavia, o que se observa é que tais políticas públicas ainda acontecem de forma compensatória, dificultando em alguns aspectos o desenvolvimento cultural dos sujeitos do campo.

O Pronera foi o "pontapé" inicial para que as demandas educacionais dos sujeitos do campo estivessem inseridas nas agendas dos governos. Assim, abriram-se "caminhos alternativos" que foram ampliados para outros grupos, e não apenas para os assentados da reforma agrária, que é o caso do Pronera. Dentre esses "caminhos", destaca-se o Procampo. Todavia, pela morosidade no repasse dos recursos para a execução das atividades, paira uma dúvida entre a universidade, os alunos e o movimento social sobre a continuidade ou não da formação de diversos alunos que esperaram ansiosos para uma educação superior de qualidade.

Essas políticas públicas são iniciativas que abrem possibilidades para formar um profissional capaz de associar os conteúdos curriculares e os saberes da experiência à necessidade e à realidade do campo. E a universidade precisa se adequar para receber e executar essas iniciativas.

Assim, julga-se importante ressaltar a apropriação que o Campus Universitário de Abaetetuba teve para com a formação dos sujeitos do campo. Isso pode ser observado pela oferta de 50 e 40 vagas para o curso de Licenciatura em Educação do Campo nos vestibulares de 2012 e 
2013, respectivamente, a fim de atender aos sujeitos do campo e a outras pessoas interessadas na discussão da temática, preferencialmente aquelas vinculadas aos movimentos sociais.

\section{REFERÊNCIAS}

BARROS, O. F. Educação popular em comunidades ribeirinhas: um estudo da participação pedagógica do educador na comunidade. In: Seminário de Educação e Movimentos Sociais do PPGE/CE/UFPB, 4. João Pessoa: UFPB, 2006.

Políticas públicas em educação ribeirinha na Amazônia: A Contribuição das Diretrizes Operacionais para a Educação. In: Encontro de Pesquisa Educacional do Norte e Nordeste, 18, Maceió, 2007.

BONNAL, P; KATO, K. O processo contemporâneo de territorialização de políticas e ações públicas no meio rural Brasileiro. In: MIRANDA, C; TIBURCIO, B. (Org.). Políticas públicas, atores sociais e desenvolvimento territorial no Brasil. Brasília: IICA, 2011. (Série desenvolvimento rural sustentável; v.14).

BRASIL, Ministério da Educação. Secretaria de Educação Continuada, Alfabetização, Diversidade e Inclusão. Procampo. Disponível: <http:// portal.mec.gov.br/index.php?option $=$ com_content\&view $=$ article\&id 12395: apresentacao\&catid $=320$ :procampo\&Itemid $=673>$. Acesso: 30/09/2011.

Lei n. 9.394, de 20 de Dezembro de 1996. Estabelece as Diretrizes e Bases da Educação Nacional. Brasília, DF, 1996. Disponível: <http://www.planalto.gov.br/ccivil_03/Leis/L9394.htm>. Acesso: 02/11/2011.

- Ministério da Educação. Conselho Nacional de Educação. Resolução CEB n. 01, 2002. Diretrizes Operacionais da Educação Básica para as Escolas do Campo. Brasília, DF, 3/04/2002.

Ministério da Educação. Instituto Nacional de Estudos e Pesquisas Educacionais Anísio Teixeira. Panorama da Educação no Campo. Brasília: INEP, 2007. 
Decreto n. 7.352, de 4 de Novembro de 2010. Dispóe sobre a política de educação do campo e o Programa Nacional de Educação na Reforma Agrária - PRONERA. Brasília, 2009.

BRANDÃO, E. C. Educação do campo: pedagogia da sobrevivência. In: CECÍLIO, M. A. BRANDÃO, E. C. Educação: campo e cidade territórios do saber. 1 ${ }^{\text {a }}$ ed. Maringá: Massoni, 2006.

FREITAS, H. C. de A. Rumos da Educação do Campo. In: MOLINA, Mônica; FREITAS, H. C. de A. (Org.). Educação do Campo. Revista em Aberto. v. 24, n. 85, Brasília: INEP, 2011.

MINISTÉRIO DO DESENVOLVIMENTO AGRÁRIO/INCRA. Manual de operações do Programa Nacional de Educação na Reforma Agrária. Edição Revista e Atualizada. Brasília, 2004.

MOLINA, Mônica; FREITAS, H. C. de A. Avanços e desafios na construção da Educação do Campo. In: MOLINA, Mônica; FREITAS, H. C. de A. (Org.). Educação do Campo. Revista em Aberto, v. 24, n. 85, Brasília: INEP, 2011.

SÁ, L. M. et al. A produção do conhecimento na formação dos educadores do campo. In: MOLINA, Mônica; FREITAS, H. C. de A. (Org.). Educação do Campo. Revista em Aberto, v. 24, n. 85, Brasília: INEP, 2011.

SOUZA, D. V. S. Currículos e saberes culturais das comunidades dos discentes ribeirinhos do curso de pedagogia das águas de Abaetetuba/Pará. Dissertação de Mestrado. Belém: PPGED/ICED/ UFPA, 2011.

TAVARES, M. G. M. O papel social da universidade na formação do educador. In: MACEBO, D.; ALBUQUERQUE, M. L. de (Org.). Universidade: políticas, avaliação e trabalho docente. São Paulo: Cortez, 2004.

UNIVERSIDADE FEDERAL DO PARÁ. Projeto Político Pedagógico do Curso de Licenciatura em Educação do Campo. Abaetetuba: UFPA/Campus Universitário de Abaetetuba, 2010.

Projeto Pedagógico do Curso de Pedagogia das Águas. Abaetetuba: UFPA/Campus Universitário de Abaetetuba, 2005. 